Article

\title{
The Analysis of Working Parameters Decrease in Photovoltaic Modules as a Result of Dust Deposition
}

\author{
Ewa Klugmann-Radziemska *(D) and Małgorzata Rudnicka *(D) \\ Department of Energy Conversion and Storage, Faculty of Chemistry, Gdansk University of Technology, \\ Narutowicza 11/12, 80-233 Gdansk, Poland \\ * Correspondence: ewa.klugmann-radziemska@pg.edu.pl (E.K.-R.); malgorzata.rudnicka@pg.edu.pl (M.R.)
}

Received: 4 June 2020; Accepted: 4 August 2020; Published: 10 August 2020

check for updates

\begin{abstract}
The aspect of dust accumulation on the surface of photovoltaic (PV) modules should be thoroughly understood in order to minimize possible obstacles affecting energy generation. Several elements affect the amount of pollutant gathered on the surface of a solar device, mainly its localization, which is irreversibly linked to factors such as annual rainfall, occasional snow coverage, or, in a dry climate, increased blow of dust during sandstorms and higher concentration of soil particles in desert areas. Other than weather conditions in the region, PV installation type also plays an important role as a more horizontal position is favorable for the accumulation of soil. The research carried out and presented in this paper was done for dust accumulated naturally on PV modules kept in outdoor conditions and dust artificially sieved onto the front glass cover of modules. The experiment performed by the authors, including artificially deposited dust, defined the linear relationship between surface dust density of different types of contaminants and efficiency decline up to $10 \%$ for two different PV modules. The additional field study carried out in external conditions for a coastal region in Northern Poland concluded that, after one year, exposition photovoltaic conversion efficiency can be over $10 \%$ lower, with a slight performance improvement for the autumn season characterized by heavy rainfall.
\end{abstract}

Keywords: dust accumulation; dust surface density; photovoltaic module; efficiency decrease

\section{Introduction}

Maximization of the energy generated by photovoltaic (PV) installations is not only connected to providing modules with enhanced efficiency but also restricting elements that may impact it in a negative way. The photovoltaic conversion efficiency of a solar module is affected by several factors, most importantly solar cell material, location and region, module working temperature, inclination angle, orientation, as well as any shadowing and dust covering the surface. The latter issue has been analyzed thoroughly. The overview of research done in the area of soil pollution was presented by Sarver [1]. Early studies linked dust buildup with the reduction of glass transmittance [2], which directly corresponds to lessened solar irradiance reaching solar cells [3]. This process could be divided into two parts: firstly, the accumulation phase responsible for a linear decrease of transparency, and the second phase of molecule deposition on top of the already existing dust layer [3,4]. Many research groups observed the correlation of short-circuit current decline with the amount of accumulated pollution on the front glass cover of PV modules [5-12]. An example of this relationship is presented in the thorough work of Al-Hasan [6] and Rao [9], as they take into consideration short-circuit current and power at the maximum power point. Their approach, however, does not account for a situation when the dust is not distributed uniformly on the whole module surface. 
Moreover, the type of soil itself is of considerable significance, as pointed out by El-Shobokshy [13,14], Kaldellis [15,16], and Aïssa [17]. Dust consisting of grains with a smaller diameter ensures a more uniform distribution on the surface, thus blocking light with better efficiency than bigger grains.

Frequent precipitation is one of the key factors affecting dust accumulation, as it may be helpful in removing some part of the pollution on the PV module's surface [18]. However, it should also be noted that high humidity facilitates molecule adhesion, thus intensifying the soiling effect $[19,20]$. Additionally, module positioning also greatly influences the overall amount of accumulated dust. The more vertical the module tilt angle is, the lesser amount of dust will affix to the glass surface [21-23].

It seems to be most productive to analyze the soiling issue in the context of the PV installation location, as it determines the average amount of dust covering the module surface, its size and composition, and the amount and intensity of precipitation. Only then can a suitable approach be introduced, since the vast majority of research on the soiling effect in PV was done for dry climates, without taking into account other environmental conditions dictated by the specificity of seaside locations. Therefore, the aim of this study was defined as introducing the relationship between the surface density of soil and the change of electrical parameters-in this case, efficiency. The suggested approach is helpful in drawing comparisons for PV modules with different electrical and physical parameters. Additionally, the influence of the glass surface is highlighted to play a significant role in the overall decrease of working parameters of any solar device.

\section{Experimental Section}

\subsection{The Study of Natural Dust Accumulation}

Four photovoltaic modules with different working parameters were fixed to the metal rack on top of the building, as presented in Figure 1. The building is located in Gdansk, the seaside town in northern Poland, and has coordinates $54^{\circ} 37^{\prime} \mathrm{N}, 18^{\circ} 62^{\prime}$ E. Their orientation was situated directly south and at a $34^{\circ}$ tilt angle with respect to the horizontal surface. Before elevating them on the rooftop, their surface was diligently scraped to remove any pollution and rinsed with isopropyl alcohol several times. The decision to place the stand with modules in external conditions helped to imitate, on a small scale, a phenomenon of dust adhesion on the actual photovoltaic installation. The same mounting position was kept through the years of 2019 and 2020.

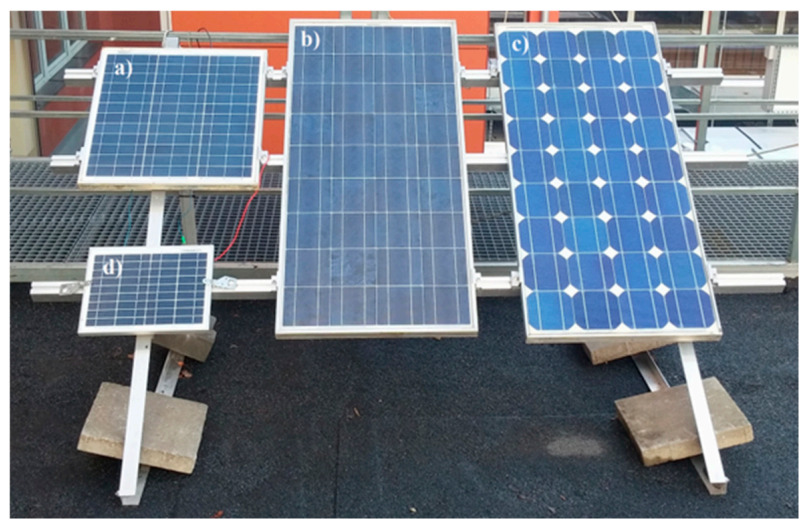

Figure 1. Photovoltaic modules chosen for the annual field study: (a) MWG-30, (b) AP-7105, (c) STP-085, (d) CLC010-12P.

Modules MWG-30, AP-7105, and STP-085 were tested each month inside the laboratory hall, and module CLC010-12P was constantly kept outside on the stand. Its purpose was to collect dust without any interruptions, which was scraped off of its surface at the end of the year. Table 1 contains parameters provided by the three analyzed photovoltaic modules' manufacturers. Bigger modules-AP-7105 and STP-085-were constructed using both monocrystalline and polycrystalline silicon, respectively. 
Table 1. Datasheet of photovoltaic (PV) modules tested inside the laboratory hall: MWG-30, AP-7105, and STP-0852.

\begin{tabular}{cccc}
\hline & MWG-30 & AP-7105 & STP-085 \\
\hline P $_{\text {MAX }}\left[\mathrm{W}_{\text {peak }}\right]$ & 30.0 & 75.0 & 85.0 \\
$\mathrm{~V}_{\text {MAX }}[\mathrm{V}]$ & 17.5 & 17.0 & 17.1 \\
$\mathrm{I}_{\text {MAX }}[\mathrm{A}]$ & 1.71 & 4.4 & 4.97 \\
$\mathrm{~V}_{\mathrm{OC}}[\mathrm{V}]$ & 21.7 & 21.0 & 21.4 \\
$\mathrm{I}_{\mathrm{SC}}[\mathrm{A}]$ & 1.83 & 4.8 & 5.32 \\
Dimensions [mm] & $680 \times 353 \times 25$ & $1210 \times 526 \times 35$ & $1195 \times 541 \times 30$ \\
Weight [kg] & 3.9 & 8.2 & 8.0 \\
Cell type & Polycrystalline & Monocrystalline & Polycrystalline \\
\hline
\end{tabular}

Figure 2 depicts the test stand intended for the monthly measurement taken inside the laboratory hall for the three modules presented above. It was possible to obtain constant $1000 \mathrm{~W} / \mathrm{m}^{2}$ irradiance conditions by placing eight halogen lamps directly perpendicular to the module surface. Each halogen lamp was adjusted separately to ensure uniform light distribution on the PV module surface. This was checked before starting each measurement by taking readouts from a few evenly distributed points on the glass surface-9 points for a smaller MWG-30 module and 12 points for bigger modules, AP-7105 and STP-085. Additionally, the surface temperature was monitored with a pyrometer so that, whenever it exceeded $30^{\circ} \mathrm{C}$, there could be a break in measurement to cool it down. Temperature measurement was taken every $30 \mathrm{~s}$ at 5 points, directly in the middle and in four corners, on the front glass cover of the PV module analyzed at that time. Once the current and voltage values were recorded, all three modules were set on the metal frame on the rooftop. Technical data for all of the measuring devices are listed in Table 2.
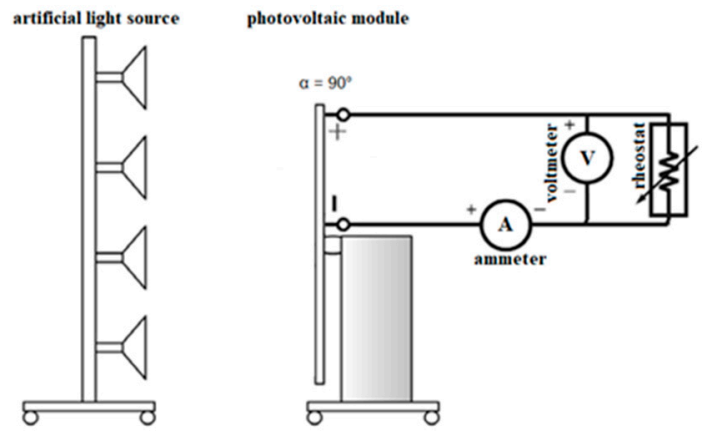

Figure 2. Scheme of the measuring unit in the laboratory hall.

Table 2. Technical data of artificial light source as well as gauging devices used for temperature, irradiance, current, and voltage measurement.

\begin{tabular}{|c|c|c|c|}
\hline Instrument & Producer & Serial Number & Description \\
\hline \multirow[t]{6}{*}{ Light source } & G.U.N.T. Hamburg & HL-313.01 & $\begin{array}{c}8 \text { halogen lamps } \\
\text { power of } 1 \text { lamp: } 1000 \mathrm{~W}\end{array}$ \\
\hline & & & Voltage measuring range: $0-200 \mathrm{~V}$ \\
\hline & & & Current measuring range: $0-20 \mathrm{~A}$ \\
\hline & G.U.N.T. Hamburg & ET-250 & Irradiance measuring range: $0-3000 \mathrm{~W} / \mathrm{m}^{2}$ \\
\hline & & & Tilt angle measuring range: $0-90^{\circ}$ \\
\hline & & & Temperature range: $0-+100^{\circ} \mathrm{C}$ \\
\hline \multirow{2}{*}{ Pyranometer } & Kipp \& Zonen & METEON 07080865 & Measuring accuracy: $0.1 \%$ \\
\hline & & & $\begin{array}{l}\text { Operating temperature: }-10-+40^{\circ} \mathrm{C} \\
\text { Measuring accuracy: } \pm 1.5^{\circ} \mathrm{C}\end{array}$ \\
\hline \multirow{3}{*}{ Pyrometer } & & & Operating temperature: $-30-+500^{\circ} \mathrm{C}$ \\
\hline & Fluke & 62 minı IR Thermometer & Sensor: laser \\
\hline & & & Standard measurement distance: $2 \mathrm{~m}$ \\
\hline
\end{tabular}




\subsection{The Study of Artificial Dust Accumulation}

At the same time, there was conducted a study aimed at artificially deposited dust. Surface mass density was chosen as a basic unit for drawing any parallels between the working parameters of photovoltaic modules. Each soil type applied in both natural and artificial dust experiments is listed in Table 3, together with location coordinates. Dust 1 corresponds to the whole pollution scraped off of MWG-30, AP-7105, and STP-085 module surfaces. Dust 2 accumulated throughout the year 2019 was collected from the additional small CLC010-12P module. The sampling point for dust 3 was located near the Chemistry Building of Gdansk University of Technology. As for dust 4, it came solely from the inside of the laboratory hall. The last two places from which dust was gathered were situated in the sandy beach area at coordinates of $54^{\circ} 41^{\prime} \mathrm{N}, 18^{\circ} 64^{\prime} \mathrm{E}$ and $54^{\circ} 41^{\prime} \mathrm{N}, 18^{\circ} 62^{\prime} \mathrm{E}$, respectively.

Table 3. Numbering of dust samples collected from photovoltaic modules, laboratory hall, and three various locations in Gdansk.

\begin{tabular}{|c|c|c|}
\hline Number & Description of Dust Sample & Coordinates \\
\hline 1 & $\begin{array}{c}\text { Taken after } 2 \text { years of deposition on MWG-30, AP-7105, and STP-085 modules } \\
\text { in outdoor conditions }\end{array}$ & $\begin{array}{l}54^{\circ} 37^{\prime} \mathrm{N} \\
18^{\circ} 62^{\prime} \mathrm{E}\end{array}$ \\
\hline 2 & Taken after 1 year of deposition on CL010-12P module in outdoor conditions & $\begin{array}{l}54^{\circ} 37^{\prime} \mathrm{N} \\
18^{\circ} 62^{\prime} \mathrm{E}\end{array}$ \\
\hline 3 & Taken from roads near Chemistry C GUT Building & $\begin{array}{l}54^{\circ} 37^{\prime} \mathrm{N} \\
18^{\circ} 62^{\prime} \mathrm{E}\end{array}$ \\
\hline 4 & Taken from laboratory hall in Chemistry C GUT Building & $\begin{array}{l}54^{\circ} 37^{\prime} \mathrm{N} \\
18^{\circ} 62^{\prime} \mathrm{E}\end{array}$ \\
\hline 5 & Taken from sand beach area near the walking pier in Gdansk & $\begin{array}{l}54^{\circ} 41^{\prime} \mathrm{N} \\
18^{\circ} 64^{\prime} \mathrm{E}\end{array}$ \\
\hline 6 & Taken from sand beach area near the tram loop in Gdansk & $\begin{array}{l}54^{\circ} 41^{\prime} \mathrm{N} \\
18^{\circ} 62^{\prime} \mathrm{E}\end{array}$ \\
\hline
\end{tabular}

The amount of dust 3, 5, and 6 initially gathered was equal to circa $0.5 \mathrm{~kg}$. Afterward, it was sieved 15-20 times with a $1 \mathrm{~mm}$ netted strainer to remove any elements that did not belong to loose debris. In order to obtain the desired layer of dust on the surface of the PV module, the pollutant was once again sieved and then sprayed with isopropyl alcohol to ensure adhesion and uniform distribution. An example of such application is shown in Figure 3.

a)

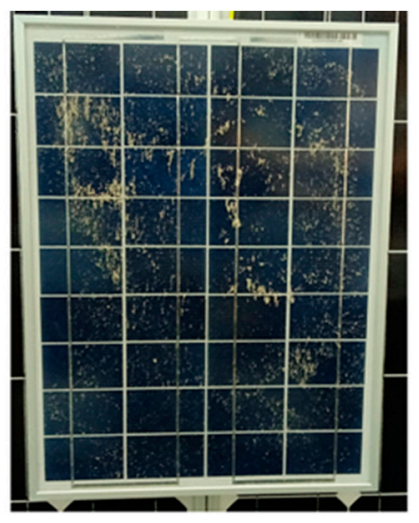

b)

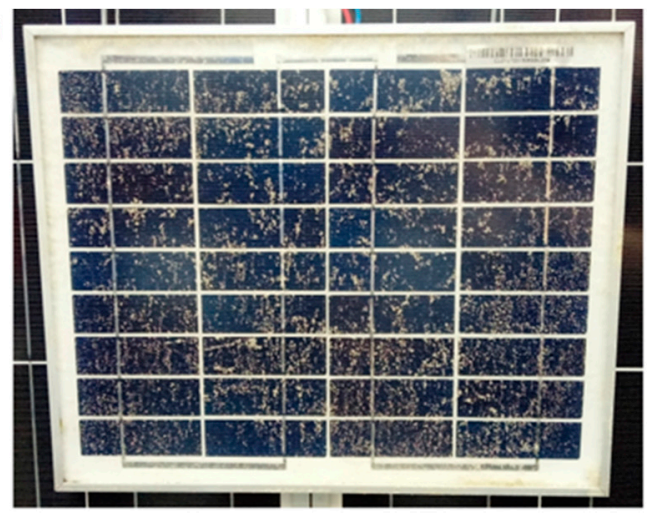

Figure 3. PV modules contaminated with around $13.2 \mathrm{~g} / \mathrm{m}^{2}$ dust density on their surface: (a) MWG-20, (b) CLC010-12P.

Throughout the whole experiment, the same two polycrystalline modules were used-MWG-20 and CLC010-12P. Their electrical parameters, as specified by the producer in the module datasheet, are presented in Table 4. 
Table 4. Datasheet of PV module MWG-20 and CLC010-12P.

\begin{tabular}{ccc}
\hline & MWG-20 & CLC010-12P \\
\hline P $_{\text {MAX }}\left[\mathrm{W}_{\text {peak }}\right]$ & 20.0 & 10.0 \\
$\mathrm{~V}_{\text {MAX }}[\mathrm{V}]$ & 17.2 & 17.5 \\
$\mathrm{I}_{\text {MAX }}[\mathrm{A}]$ & 1.17 & 0.57 \\
$\mathrm{~V}_{\text {OC }}[\mathrm{V}]$ & 21.8 & 22.0 \\
$\mathrm{I}_{\mathrm{SC}}[\mathrm{A}]$ & 1.23 & 0.63 \\
Dimensions [mm] & $505 \times 353 \times 28$ & $340 \times 280 \times 17$ \\
Weight $[\mathrm{kg}]$ & 2.3 & 1.1 \\
Cell type & Polycrystalline & Polycrystalline \\
\hline
\end{tabular}

\section{Results and Discussion}

\subsection{The Study of Natural Dust Accumulation}

The efficiency for MGW-30, AP-7105, and STP-085 modules was calculated on the basis of current-voltage characteristics taken inside the laboratory hall, under an artificial light source. Data were collected from January 2019 to November 2019, and, apart from one-time monthly measurements, the modules were placed outdoors and, as such, were subjected to atmospheric dust buildup.

All modules experienced a clear decrease in efficiency over the course of four meteorological seasons, with exact values visualized in Figure 4 . To represent the variability among data, standard error of the mean was assumed for each column because it provides the accuracy of a sample mean. The biggest loss in spring, over 15\%, was noted for MWG-30, while the remaining two experienced a much lower reduction, around several percentages. In summer, the opposite effect was observed; efficiency decline was greater for AP-7105 and STP-085 modules, namely $12 \%$ and 7\%, respectively, with only around 3\% for MWG-30. An interesting pattern emerged during the autumn months, as all three PV modules seem to have recovered part of their power. This may be caused by heavy precipitation that is characteristic of that time and location in the north of Poland.

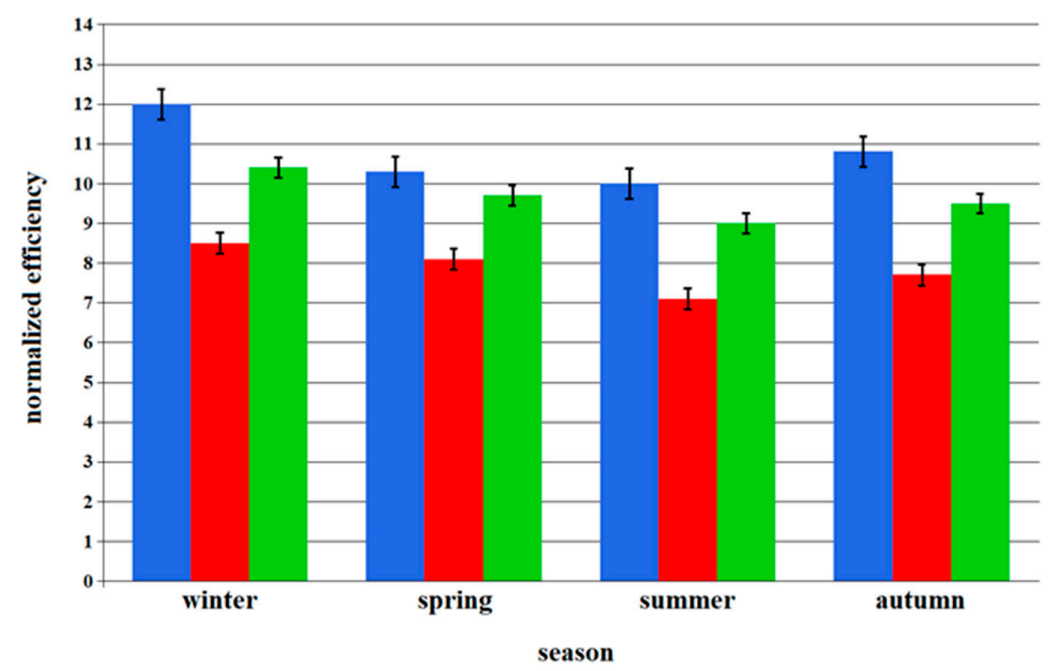

Figure 4. Average efficiency in year 2019 for different PV modules: (口) MWG-30, (口) AP-7105, (口) STP-085. Standard error of the mean is illustrated as a black bar for each value column.

\subsection{SEM and EDS Analysis of Natural Dust}

Uneven molecular structure of both dust 1 and dust 2 was captured by means of scanning electron microscopy (SEM)-Figure 5. Grains differ in size from one another; some have sharply defined edges, while the build of others resembles sponges. In a few places, there is a higher concentration of 
molecules, which leads to the conclusion that an agglomeration process has already happened over the course of one year, as new pollutant particles gather on top of the old ones.

a)

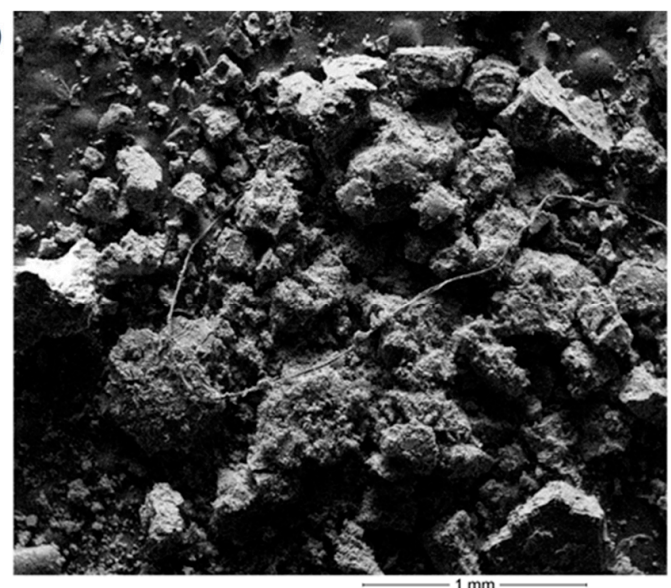

b)

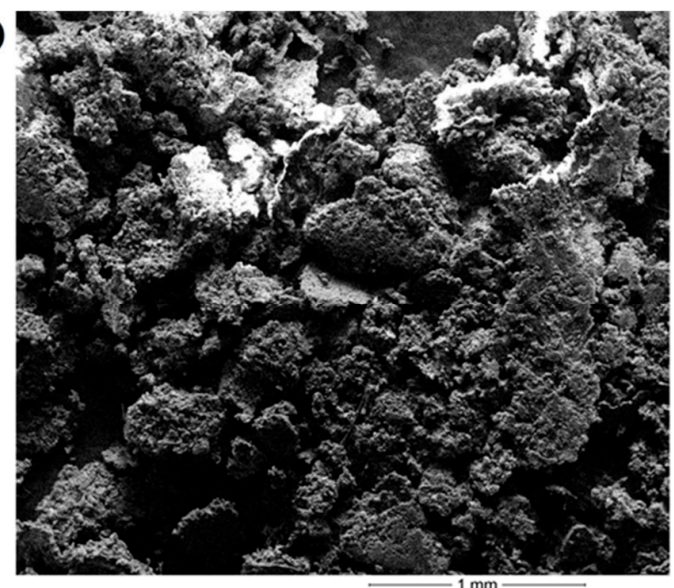

Figure 5. SEM photograph: (a) dust 1 (magnification 43×), (b) dust 2 (magnification $42 \times$ ).

EDS spectra presented in Figure 6 indicate that both pollutants contain considerable content of oxygen, silicon, aluminum, and trace quantities of iron and magnesium. The carbon peak visible in both graphs is a result of using carbon tape during this measurement and should not be counted as part of dust 1 or 2 . Dust 1 has much bigger sulfur content and additional weak peaks from chlorine. In contrast to this pollutant, silicon and oxygen exhibit much stronger intensity in the EDS spectrum for dust 2. The peak for potassium in dust 2 is also different, with much higher intensity, and trace elements of calcium, phosphorous, and titanium appear. That big of a difference in composition between dust 1 and dust 2 could be caused by the specific conditions during the accumulation period in 2019 when construction work directly in front of the location took place for a majority of that year.
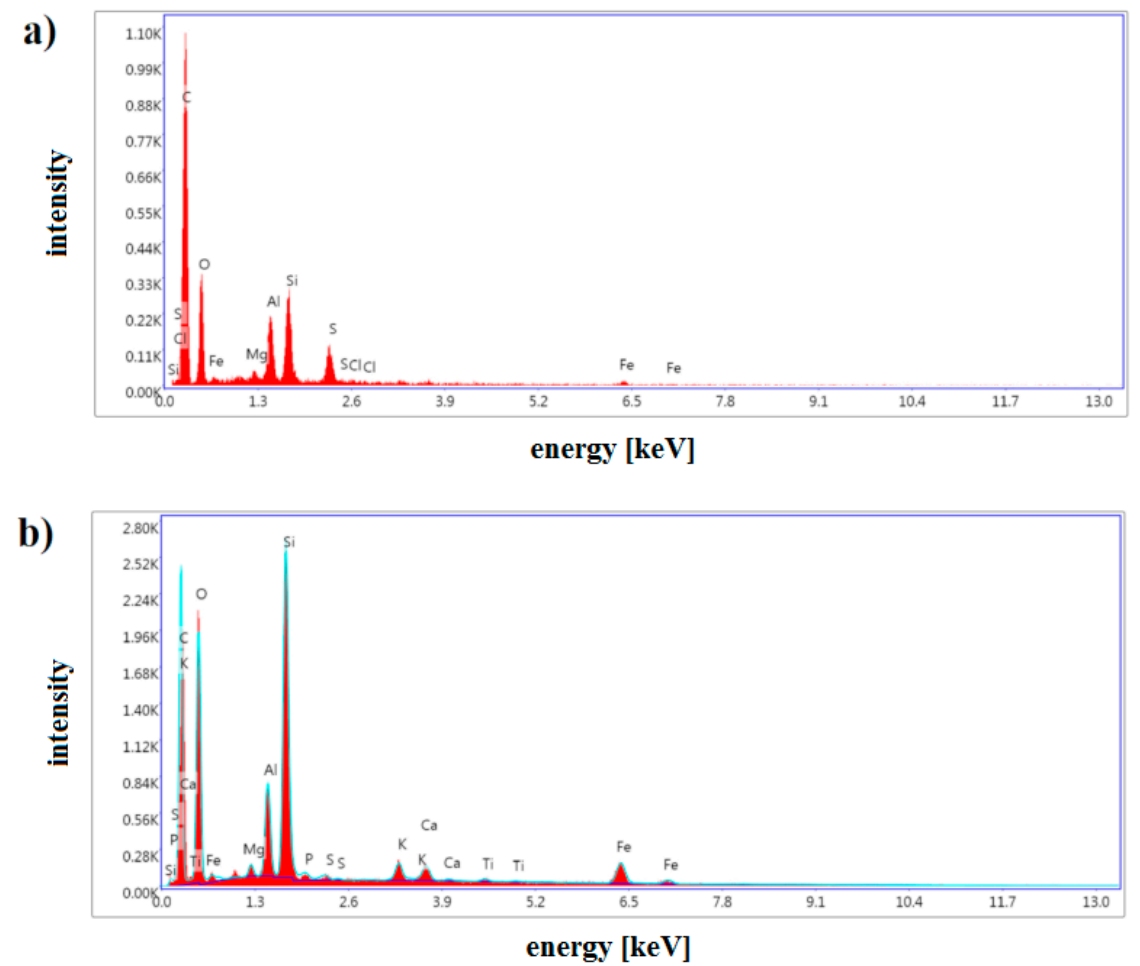

Figure 6. EDS graph for: (a) dust 1, (b) dust 2. 


\subsection{The Study of Artificial Dust Accumulation}

Another part of the study was conducted on dust manually sieved above the PV module surface. For this purpose, dust 3, 5, and 6 were used, and two polycrystalline PV modules, MWG-20 and CLC010-12P, were chosen. Irradiance and surface temperature were kept respectively at $1000 \mathrm{~W} / \mathrm{m}^{2}$ and $30{ }^{\circ} \mathrm{C}$. Normalized efficiency was calculated based on obtained current-voltage characteristics, as the efficiency obtained for maximum power generated by the polluted module divided by the efficiency for maximum power generated by the clean module. Both modules were produced as polycrystalline silicon solar cells; however, their response to pollutants was slightly different, as seen in Figure 7. Below $15 \mathrm{~g} / \mathrm{m}^{2}$, CLC010-12P faced higher efficiency losses, no matter the type of contaminant applied. Already, $3 \mathrm{~g} / \mathrm{m}^{2}$ of surface dust density caused a decrease of nearly $5 \%$ of efficiency for this module. For the dust density of the order of $10 \mathrm{~g} / \mathrm{m}^{2}$, this number was even higher and reached around $10 \%$. MWG-20 seemed to better cope with soil contamination, as its efficiency was never reduced by more than $6 \%$ for each of the three pollutants.
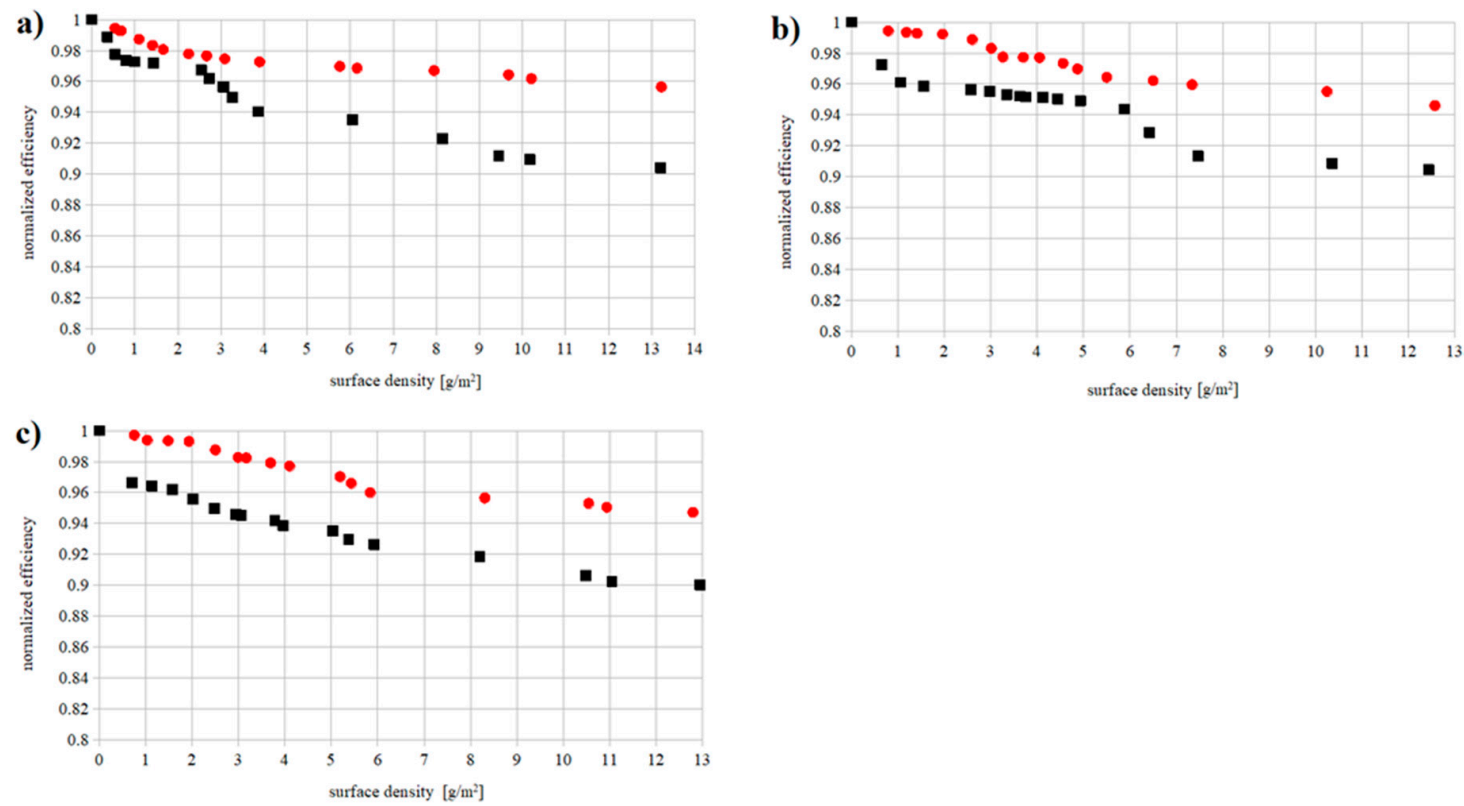

Figure 7. Normalized efficiency $\eta / \eta_{\mathrm{MAX}}$ for: (a) dust 3 , (b) dust 5 , (c) dust 6 , covering the surface of two PV modules-(•) MWG-20 and (घ) CLC010-12P.

The analysis was supposed to imitate outdoor conditions that allowed for dust accumulation on PV module surfaces. All three contaminants caused a linear efficiency decrease, which could be attributed to the first phase of dust accumulation reported by many research groups $[4,6,9,13]$. The efficiency, however, did not decrease as abruptly as was noted for some other measurements using artificial pollution in laboratory conditions [6-9]. The average efficiency reduction obtained in this research for each $1 \mathrm{~g} / \mathrm{m}^{2}$ of dust accumulated on PV module surfaces was $0.77 \%$ for CLC-010-12P and $0.38 \%$ for MWG-20.

Figure 8 gives a better focus on the issue of contamination for a fixed surface density of $10.4 \mathrm{~g} / \mathrm{m}^{2}$. The efficiency decline was calculated as a ratio of efficiency $\eta$ after soil contamination to the efficiency $\eta_{0}$ of a clean module. For all three types of dust, it equaled the average of 4.3\% for MWG-20 and 9.2\% for CLC010-12P. This varying response cannot be explained by the type of module or dust since both were manufactured in the same technology and polluted with only a specific type of dust. The factor of dust composition influencing the electric response in MWG-20 and CLC010-12P may be omitted, as they were both polluted with the same dust type at the time of carrying out the exact measurement. Most probably, it was caused by the glass layer itself, as it is supposed to change in PV modules 
produced by different companies. This conclusion is supported by an analysis of results obtained by two independent research groups-under Cabanillas' [24] and Gandhi's [25] supervision. Efficiency decrease acquired in those experiments does not appear to exhibit any correlation to the solar cell type (monocrystalline or polycrystalline).

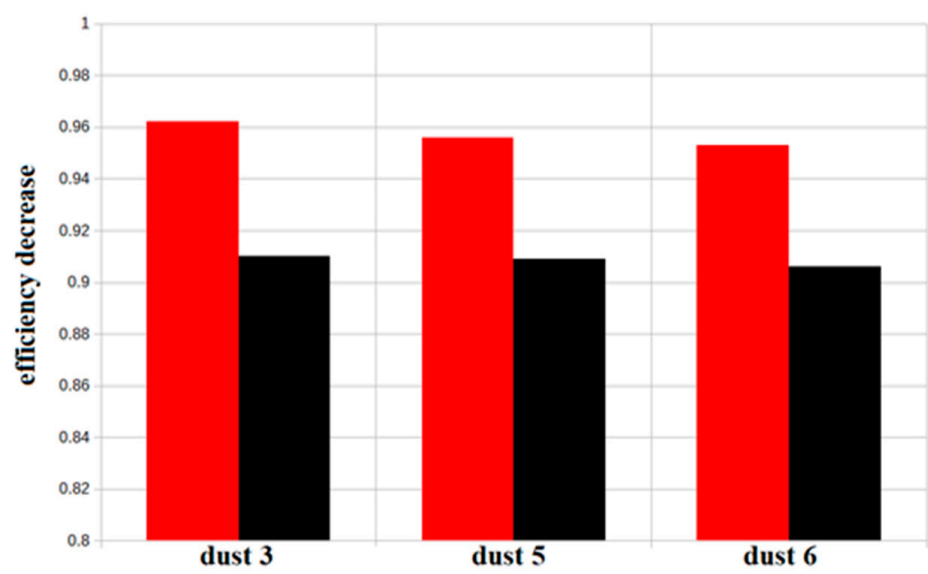

Figure 8. Efficiency decrease $\eta / \eta_{0}$ for surface dust density of around $10.4 \mathrm{~g} / \mathrm{m}^{2}$ covering PV module: (») MWG-20 and (») CLC010-12P.

\subsection{SEM and EDS Analysis of Artificial Dust}

Pictures taken by SEM in Figure 9 present dust types gathered from three different outside locations and from the laboratory hall. Unlike in Figure 5, all of them have well-defined edges. Varying grain size with distinctive cracks in some places characterizes pollution occupying roads near the university campus (Figure 9a), as well as the inside of the laboratory hall (Figure 9b). Dust 3 consists of elements of two distinct sizes-smaller grains with an average diameter of around $0.2 \mathrm{~mm}$, and bigger ones with an average diameter of roughly $0.45 \mathrm{~mm}$. The average grain size for dust 4 is in the range of $0.2-0.35 \mathrm{~mm}$, with some noticeably bigger parts exceeding $0.5 \mathrm{~mm}$. Two types of soil gathered from a sampling point located at a short distance from the beach contain grains with a similar diameter, which have more even edges and are less fractured. The average grain diameter for dust 5 (Figure 9c) falls in the range of $0.23-0.36 \mathrm{~mm}$ and for dust 6 (Figure $9 \mathrm{~d}$ ) in the range of $0.22-0.33 \mathrm{~mm}$.
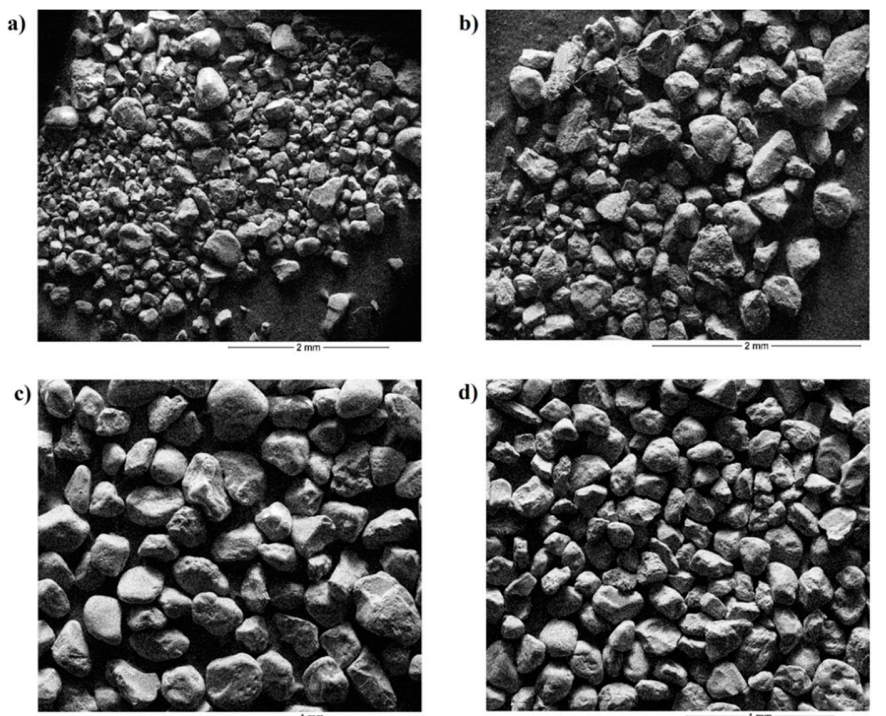

Figure 9. SEM photograph: (a) dust 3 (magnification $26 \times$ ), (b) dust 4 (magnification $34 \times$ ), (c) dust 5 (magnification 53×), (d) dust 6 (magnification $49 \times$ ). 
EDS spectra in Figure 10 correspond to dusts 3, 4, 5, and 6, respectively. Dust 3 (Figure 10a) consists mainly of calcium, oxygen, silicon, and aluminum; however, trace elements of potassium, magnesium, and iron were also recorded. An additional peak from carbon comes from carbon tape and is, by no means, a part of this pollutant. The composition of dust 4 (Figure 10b) is characterized by two distinctive peaks-one with high intensity for silicon and the other with medium intensity for an oxygen peak, surrounded with the marginal presence of calcium, chlorine, potassium, sodium, and sulfur. Dusts 5 (Figure 10c) and 6 (Figure 10d) are less differentiated element-wise than other types of pollutants. Their sampling points were in close proximity to the beach, which heavily influenced grain composition. It comprises two explicitly visible peaks, correlating to silicon and oxygen. Dust 6 has a more diversified structure with additional peaks from calcium and potassium. On this basis, it was established that two gathered pollutants-dust 3 and dust 6 - might be used for experimental studies concerning artificial soil influence because of a strong convergence in composition with regard to natural pollutants as dusts 1 and 2. Both dusts 3 and 6 contain strong intensity peaks from silicon and oxygen, as well as trace elements of aluminum, calcium, and potassium. A slightly closer fit could be attributed to dust 6 since calcium, potassium, and iron in its EDS spectrum exhibit small intensity peaks. It should be noted that this conclusion is valid for a specific location that is at $54^{\circ} 37^{\prime} \mathrm{N}$ $18^{\circ} 62^{\prime}$ E coordinates
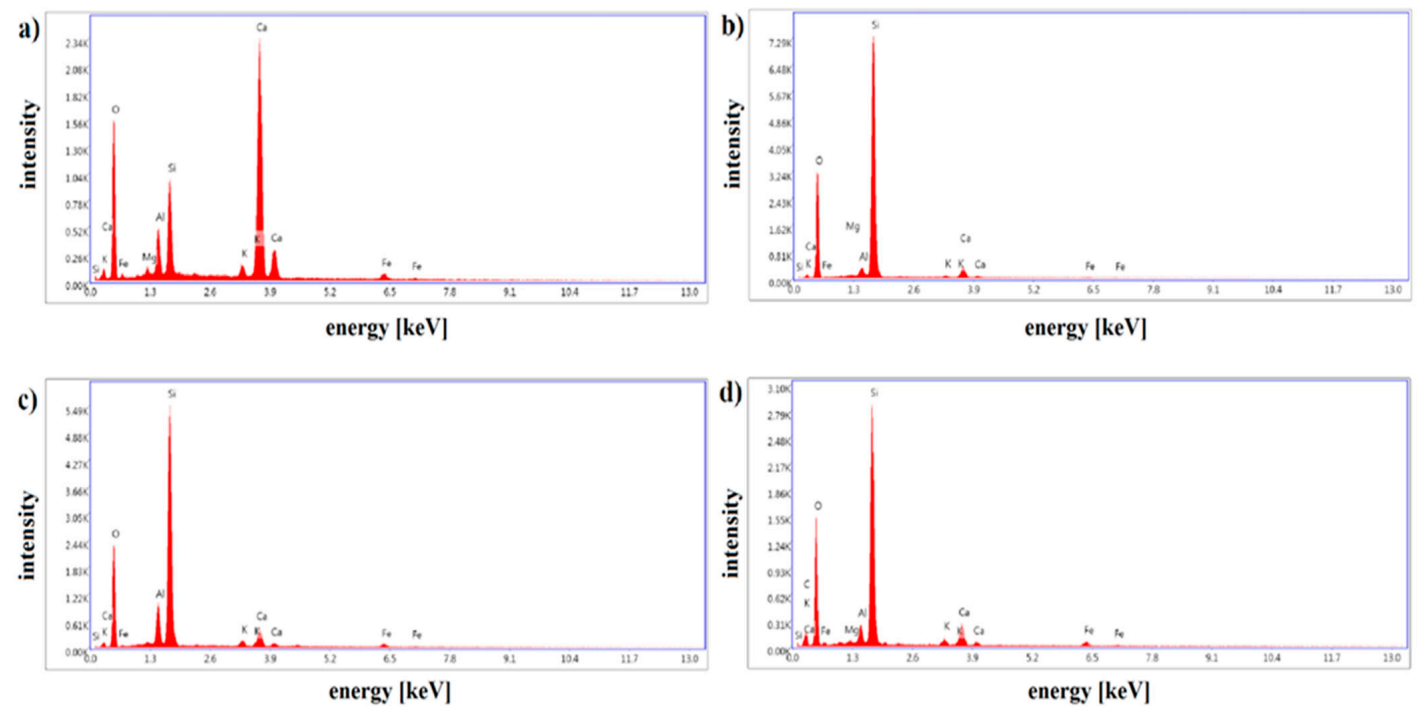

Figure 10. EDS graph for: (a) dust 3, (b) dust 4, (c) dust 5, (d) dust 6.

\section{Conclusions}

Reduced conversion efficiency observed for PV modules after dust deposition is a considerable issue as it leads to generated energy reduction and economic viability shrinkage. The rate of contaminant deposition is linked to a number of factors heavily dependent on the PV installation location. It will, therefore, impact some modules much greater than others situated in regions less prone to dust accumulation.

It should be emphasized that the amount of contaminants collected on the surface is not proportionate to the time of exposure. This is related to the significant impact of precipitation and wind. This is why any comparison of average effects should also include analyzing the location in relation to the environment (agricultural crops, deserts, traffic, or industrial activity in the near vicinity) and the pollutant composition.

A comprehensive analysis of both natural and artificial dust was carried out at Gdansk University of Technology through all of 2019. It provided more insight into the hard-shading effect and its consequences for possible power generation. Overall, there was a significant decline in efficiency for the whole year; however, in autumn, it recovered a few percentile points. This effect can be 
linked to rinsing a part of the accumulated dust off by heavy precipitation occurring frequently in this meteorological season since the modules are located in the temperate, coastal climate in the northern hemisphere.

Additionally, experiments conducted on two different solar modules using artificial dust of varying origin provided data for drawing a linear relationship of efficiency decrease and different surface densities, thus confirming data cited in literature by other research groups. Provided the process of applying artificial pollutants maintains its uniform distribution over the PV module surface, all thee dusts (dust 3, dust 5, and dust 6) could be used for the laboratory analysis of the soiling effect affecting working parameters of PV devices. A significant decrease in the efficiency of photovoltaic modules was observed, caused by the deposition of impurities, depending on the thickness of the dust layer and its morphology, but it is different for the two modules tested. This means that the structure of the glass surface constituting the top layer of the module plays an important role and should not be neglected in such analysis.

Author Contributions: Conceived and designed the analysis, E.K.-R.; Performed the analysis, E.K.-R.; Wrote the paper, E.K.-R. and M.R.: Collected the data, M.R.; Contributed data or analysis tools, M.R. All authors have read and agreed to the published version of the manuscript.

Funding: Subsidy of the Polish Ministry of Science and Higher Education.

Acknowledgments: The authors gratefully acknowledge the contribution of M. Winiarski from the Department of Solid-State Physics, Faculty of Applied Physics and Mathematics, at Gdansk University of Technology for performing SEM and EDS measurements.

Conflicts of Interest: The authors declare no conflict of interest.

\section{References}

1. Sarver, T.; Al-Qaraghuli, A.; Kazmerski, L.L. A comprehensive review of the impact of dust on the use of solar energy: History, investigations, results, literature and mitigation approaches. Renew. Sustain. Energy Rev. 2013, 22, 698-733. [CrossRef]

2. Hottel, H.C.; Woertz, B.B. The performance of flat plate solar heat collectors. ASME Trans. 1942, 64, 91-104.

3. Al-Hasan, A. A new correlation for direct beam solar radiation received by photovoltaic panel with sand dust accumulated on its surface. Sol. Energy 1998, 63, 323-333. [CrossRef]

4. Beattie, N.S.; Moir, R.S.; Buffoni, G. Understanding the effects of sand and dust accumulation on photovoltaic modules. Renew. Energy 2012, 48, 448-452. [CrossRef]

5. Häberlin, H.; Graf, J.D. Gradual Reduction of PV Generator Yield due to Pollution. In Proceedings of the 2nd World Conference and Exhibition on Photovoltaic Solar Energy Convention, Vienna, Austria, 6-10 July 1998.

6. Al-Hasan, A.; Ghoneim, A.A. A new correlation between photovoltaic panels efficiency and amount of sand dust accumulated on their surface. Int. J. Sustain. Energy 2005, 24, 187-197. [CrossRef]

7. Sulaiman, S.A.; Hussain, H.H.; Leh, N.S.H.N.; Razali, M.S.I. Effects of dust on the performance of PV panels. Int. J. Mech. Mechatron. Eng. 2011, 5, 2028-2033.

8. Benatiallah, A.; Ali, M.; Abidi, F.; Benatiallah, D.; Harrouz, A.; Mansouri, I. Experimental study of dust effect in mult-crystal PV solar module. IJMSE 2012, 3, 1-4.

9. Rao, A.; Pillai, R.; Mani, M.; Ramamurthy, P. Influence of dust deposition on photovoltaic panel performance. Energy Procedia 2013, 54, 690-700. [CrossRef]

10. Sulaiman, S.A.; Singh, A.K.; Mokhtar, M.M.M.; Bou-Rabee, M. Influence of dirt accumulation on performance of PV panels. Energy Procedia 2014, 50, 50-56. [CrossRef]

11. Gholami, A.; Khazaee, I.; Eslami, S.; Zandi, M.; Akrami, E. Experimental investigation of dust deposition effects on photovoltaic output performance. Sol. Energy 2018, 159, 346-352. [CrossRef]

12. Gostein, M.; Düster, T.; Thuman, C. Accurately Measuring PV Soiling Losses with Soiling Station Employing Module Power Measurements. In Proceedings of the 42nd IEEE Photovoltaic Specialist Conference (PVSC), New Orleans, LA, USA, 14-19 June 2015.

13. El-Shobokshy, M.S.; Hussein, F.M. Effect of the dust with different physical properties on the performance of photovoltaic cells. Sol. Energy 1993, 51, 505-511. [CrossRef] 
14. El-Shobokshy, M.S.; Hussein, F.M. Degradation of photovoltaic cell performance due to dust deposition on its surface. Renew. Energy 1993, 3, 585-590. [CrossRef]

15. Kaldellis, J.K.; Kapsali, P.M. Simulating the dust effect on the energy performance of photovoltaic generators based on experimental measurements. Energy 2011, 36, 5154-5161. [CrossRef]

16. Kaldellis, J.K.; Fragos, P.; Kapsali, M. Systematic experimental study of the pollution deposition impact on the energy yield of photovoltaic installations. Renew. Energy 2011, 36, 2717-2724. [CrossRef]

17. Aïssa, B.; Isaifan, R.J.; Madhavan, V.E.; Abdallah, A.A. Structural and physical properties of the dust particles in Qatar and their influence on the PV panel performance. Sci. Rep. 2016, 6, 1-12. [CrossRef]

18. Styszko, K.; Jaszczur, M.; Teneta, J.; Hassan, Q. An analysis of the dust deposition on solar photovoltaic modules. Environ. Sci. Pollut. Res. 2019, 26, 8393-8401. [CrossRef]

19. Paudyal, B.R.; Shakya, S.R. Dust accumulation effects on efficiency of solar PV modules for off grid purpose: A case study of Kathmandu. Sol. Energy 2016, 135, 103-110. [CrossRef]

20. Yadav, S.K.; Bajpai, U. Variation in the performance of solar photovoltaic power plant due to climatic parameters in composite climatic zone. IJETER 2017, 5, 67-72.

21. Hegazy, A.A. Effect of dust accumulation on solar transmittance through glass covers of plate-type collectors. Renew. Energy 2001, 22, 525-540. [CrossRef]

22. Appels, R.; Muthirayan, B.; Beerten, A.; Paesen, R.; Driesen, J.; Poortmans, J. The Effect of Dust Deposition on Photovoltaic Modules. In Proceedings of the 2012 38th IEEE Photovoltaic Specialists Conference, Austin, TX, USA, 3-8 June 2012; pp. 001886-001889. [CrossRef]

23. Elminir, H.K.; Ghitas, A.E.; Hamid, R.H.; El-Hussainy, F.; Beheary, M.M.; Abdel-Moneim, K.M. Effect of dust on the transparent cover of solar collectors. Energy Convers. Manag. 2006, 47, 3192-3203. [CrossRef]

24. Cabanillas, R.; Munguia, H. Dust accumulation effect on efficiency of Si photovoltaic modules. J. Renew. Sustain. Energy 2011, 3. [CrossRef]

25. Gandhi, A.T.; Gupta, A.; Vijay, B.S. Investigation of the effects of dust accumulation and performance for mono and poly crystalline silica modules. Int. J. Renew. Energy Res. 2014, 4, 628-634.

(C) 2020 by the authors. Licensee MDPI, Basel, Switzerland. This article is an open access article distributed under the terms and conditions of the Creative Commons Attribution (CC BY) license (http://creativecommons.org/licenses/by/4.0/). 